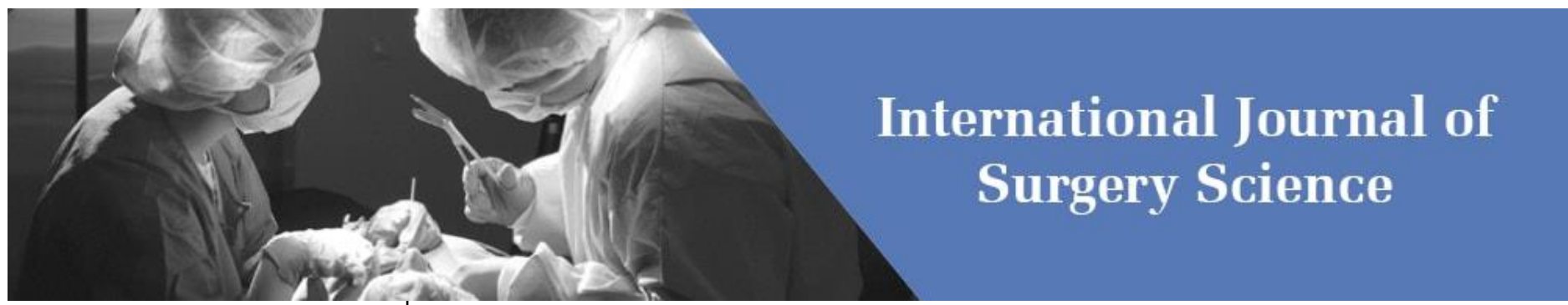

E-ISSN: 2616-3470

P-ISSN: 2616-3462

(C) Surgery Science www.surgeryscience.com

2019; 3(2): 123-124

Received: 04-02-2019

Accepted: 08-03-2019

\section{A Mejouar}

Service de dermatologie et de vénéréologie, Faculté de médecine et de pharmacie. Université Hassan II, Casablanca, Morocco

\section{FEl Fatoik}

Service de dermatologie et de vénéréologie, Faculté de médecine et de pharmacie. Université Hassan II, Casablanca, Morocco

\section{F Hali}

Service de dermatologie et de vénéréologie, Faculté de médecine et de pharmacie. Université Hassan II, Casablanca, Morocco

S Chiheb

Service de dermatologie et de vénéréologie, Faculté de médecine et de pharmacie. Université Hassan II, Casablanca, Morocco
Correspondence

A Mejouar

Service de dermatologie et de vénéréologie, Faculté de médecine et de pharmacie. Université Hassan II, Casablanca, Morocco

\section{Congenital juvenile xanthogranuloma: About a case}

\author{
A Mejouar, FEI Fatoiki, F Hali and S Chiheb
}

DOI: https://doi.org/10.33545/surgery.2019.v3.i2c.22

Abstract

Introduction: Juvenile xanthogranuloma is a non-Langer hansian histiocytosis. In 5 to $17 \%$ of cases the lesions are present at birth. We report a new case of congenital juvenile xanthogranuloma.

Case report: A four-month-old female infant with no significant pathological history had a single nodular lesion $1 \mathrm{~cm}$ in diameter at the left knee flexion surface gradually increasing in size, orange-yellow in color, with squamous surface, with regular contours, firm and painless, with no extracutaneous signs or associated signs of Neurofibromatosis type 1 .

Histological examination found juvenile xanthogranuloma with a dermis containing dilated lymphatic ducts with a foamy, histiocytic interstitial infiltrate and hyperplastic epidermis.

Discussion: It is a benign cutaneous lesion of infants and young children. The cephalic extremity and the nape of the neck are preferentially affected, but the lesions can also occur on the trunk and the extension faces of the extremities. The evolution is generally favorable and the lesion regresses spontaneously in almost all cases.

Conclusion: Juvenile xanthogranuloma is a benign cutaneous tumor. Nevertheless, cases of fatal evolution are reported in multiple locations from where the interest of a careful clinical examination with search for signs of extra-cutaneous appeal.

Keywords: xanthogranuloma, juvenile, congenital

\section{Introduction}

Juvenile xanthogranuloma a non-langer hansian histiocytosis.

In 5 to $17 \%$ of cases the lesions are present at birth. We report a new case of congenital juvenile xanthogranuloma.

\section{Observation}

A four-month-old female infant with no significant pathological history had a single nodular lesion of $1 \mathrm{~cm}$ in diameter at the flexion surface of the left knee (Figure 1), gradually increasing in size, orange-yellow in color, with squamous surface, with regular contours, of firm and painless consistency. The child was in very good general condition. The rest of the skin examination was without particularity, especially no sign of Neurofibromatosis type 1. Ganglionic areas were free, there was no hepatosplenomegaly and no other symptoms.

Histological examination found juvenile xanthogranuloma with a dermis containing dilated lymphatic ducts with a foamy, histiocytic interstitial infiltrate and hyperplastic epidermis. We opted for therapeutic abstention.

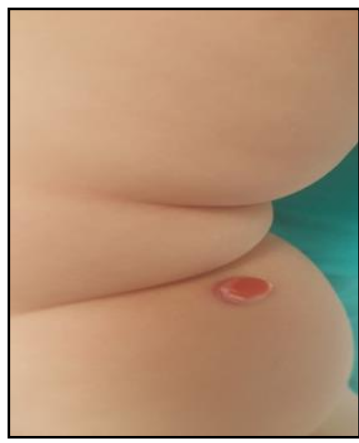

Fig 1: Nodule siégeant au niveau de la face de flexion du genou gauche 


\section{Discussion}

Juvenile xanthogranuloma is a benign cutaneous lesion. The first case of juvenile xanthogranuloma was reported in 1905 as congenital xanthoma multiplex. The term juvenile xanthogranuloma (XGJ) was used from $1954^{[1]}$.

It is a plasmocyto-monocyte proliferation, in response to an unknown etiological agent and is characterized by an accumulation of macrophages loaded with lipids, without associated lipid disorder ${ }^{[1,2]}$.

Juvenile Xanthogranuloma (XGJ) is one of the most common skin tumors in children, but its prevalence is not known.

It appears most often in the first months of life (40 to $70 \%$ ), the congenital form is rare and represents only 5 to $17 \%$ (1) which is the peculiarity of our observation ${ }^{[2]}$.

Rare cases have been described in adolescents and even adults [3].

The natural evolution is marked by a possible growth during the first months of life then a spontaneous regression between 6 months and 3 years ${ }^{[4,5]}$.

Clinically, it is a well-defined, firm, round or oval papule or nodule of yellow-orange, brown, pink or red color. Its size varies from 0.5 to $2 \mathrm{~cm}$ in diameter. It is most often asymptomatic but it can ulcerate.

It is generally unique, multiple eruptive forms have been described.

The preferred areas are head and neck, trunk and limbs but all locations are possible ${ }^{[2,6,7]}$.

The characteristic histopathologic image is that of a dense, welldefined dermal cell infiltrate composed of histiocytes of variable size and shape, as well as an inflammatory granuloma composed of lymphocytes, eosinophilic poly-nuclear cells and sometimes neutrophils, giant cells, Touton cells. The in filtrate sometimes thinens the epidermis, even the ulcer.

Apart from the rare complications associated with visceral involvement, especially in multiple forms, the prognosis is usually good, with spontaneous resolution of the lesions within a few months or years.

\section{Conclusion}

Juvenile xanthogranuloma is a benign skin tumor. Nevertheless, cases of fatal evolution are reported in multiple locations from where the interest of a careful clinical examination with search for extra-cutaneous signs.

\section{Conflict of interest}

All authors have no conflict of interest.

\section{References}

1. Kupfer-Bessaguet I, Staroz F, Plantin P, the French Pediatric Dermatology Society. Xanthogranuloma juvenile. Ann Dermatol Venereol. 2009; 136:70-3.

2. Hernandez-Martin A, Baselga E, Drolet BA, Esterly NB. Juvenile xanthogranuloma. J Am Acad Dermatol. 1997; 36:355-67.

3. Tanyeri H, Weisenberg E, Friedman M. Juvenile xanthogranuloma of the tongue. Otolaryngol Head neck surg. 2000; 123:641-2.

4. Ang P, Tay YK. Anetoderma in a patient with juvenile xantho-granuloma. Br J Dermatol. 1999; 140:541-2.

5. Gass J, Burrows N. Papular juvenile xanthogranuloma in platein an infant. Pediatr Dermatol. 2008; 25:415.

6. Flaitz C, Allen C, Neville B, Hicks J. Juvenile xanthogranuloma of the oral cavity in children: a clinicopathologic study. Oral Oral Surg Med Oral Oral
Pathol Radiol Endod. 2002; 94:345-52.

7. Castilla EA, Ormsby A. Adult xanthogranuloma of the vulva: case report and review. Pathology. 2002; 34:86-7. 